\title{
Penerapan Model Pembelajaran Inkuiri Terbimbing dalam Peningkatan Aktivitas dan Hasil Belajar IPA Tentang Gaya Di Kelas V SD Negeri 3 Kalirejo Tahun Ajaran 2017/2018
}

\author{
1,2,3 Universitas Sebelas Maret \\ devi_retna@ymail.com
}

Devi Retnaningsih', Joharman², Suhartono ${ }^{3}$

\section{Article History \\ accepted 01/02/2019}

approved 01/03/2019 published 01/04/2019

\begin{abstract}
The objectives of this research are: (1) to describe the implementation of guided inquiry learning model in improving learning activity and learning outcomes about force, (2) to improve students' learning activity, (3) to improve students' learning outcomes about force, and (4) to describe problems and solutions on the implementation of guided inquiry learning model in improving learning activity and learning outcomes about force in fifth grade class. This research is a collaborative Classroom Action Research (CAR) conducted within three cycles. Subjects of the research were teacher and 25 students of the fifth grade of SD Negeri 3 Kalirejo. The results of this research show that: (1) the steps on the implementation of guided inquiry learning model are orientation, stating the problem, predicting hypothesis, collecting the data, testing hypothesis, and drawing conclusion; (2) the implementation of guided inquiry learning model can improve learning activity and learning outcomes about force for the fifth grade students SD Negeri 3 Kalirejo. It was proven by the increase in the observation of learning activity in the first cycle $67.35 \%$, in the second cycle $83 \%$, and in the third cycle $87.08 \%$ respectively; (3) the implementation of guided inquiry learning model can improve learning outcomes about force for the fifth grade students $S D$ Negeri 3 Kalirejo. It was proven by the increase of students' learning outcomes in the first cycle $77.08 \%$, in the second cycle $88 \%$, and in the third cycle 96\% respectively; and (4) the problems encountered in the implementation of guided inquiry learning model, namely: (a) the large number of students makes it difficult for teachers to provide intensive supervision and guidance to students; (b) it is only certain student actively engaging in learning activities; (c) teaching and learning process takes a long time; and (d) some students lack awareness in completing group tasks. Solutions for these problems are: (a) teachers increase the intensity of guidance and supervision in learning to students; (b) teachers provide motivation and give opportunity to all students so that they are active in learning; (c) teachers should be better in managing time allocation for learning; and (d) teachers divides the tasks to the students in a group so that all students play an active role in completing the group task.
\end{abstract}

Keywords: guided inquiry, learning activity, learning outcome

\begin{abstract}
Abstrak
Tujuan penelitian ini adalah (1) mendeskripsikan penerapan model pembelajaran inkuiri terbimbing dalam peningkatan aktivitas belajar dan hasil belajar IPA tentang gaya; (2) meningkatkan aktivitas belajar siswa; (3) meningkatkan hasil belajar IPA tentang gaya; dan (4) mendeskripsikan kendala dan solusi dalam penerapan model pembelajaran inkuiri terbimbing dalam peningkatan aktivitas belajar dan hasil belajar IPA tentang gaya di kelas V. Penelitian tindakan kelas ini merupakan penelitian kolaboratif dilakukan selama tiga siklus. Subjek penelitian dalam penelitian ini adalah siswa kelas V SD Negeri 3 Kalirejo tahun ajaran 2017/2018 yang berjumlah 25 siswa. Hasil penelitian menunjukan bahwa: (1) penerapan model pembelajaran inkuiri terbimbing dilakukan dengan langkah orientasi, merumuskan masalah, mengajukan hipotesis, mengumpulkan data, menguji hipotesis, dan merumuskan kesimpulan; (2) penerapan model pembelajaran inkuiri terbimbing dapat meningkatkan aktivitas belajar siswa kelas V SD
\end{abstract}


Negeri 3 Kalirejo yang dibuktikan dengan adanya peningkatan hasil observasi aktivitas belajar pada setiap siklusnya. Pada siklus I sebesar $67,35 \%$, pada siklus II sebesar $83 \%$, dan pada siklus III sebesar 87,08\%; (3) penerapan model pembelajaran inkuiri terbimbing dapat meningkatkan hasil belajar tentang gaya siswa kelas V SD Negeri 3 Kalirejo yang diketahui dari ketuntasan hasil belajar siswa pada siklus I sebesar $77,08 \%$, pada siklus II sebesar $88 \%$, dan pada siklus III sebesar $96 \%$; (4) Kendala yang dihadapi saat pembelajaran meliputi: (a) jumlah siswa yang cukup banyak menyebabkan guru sulit memberikan pengawasan dan bimbingan yang intensif terhadap siswa; (b) siswa tertentu yang terlibat aktif kegiatan pembelajaran; (c) pembelajaran memerlukan waktu yang lama; (d) beberapa siswa kurang memiliki kesadaran dalam menyelesaikan tugas kelompok. Solusi dari kendala tersebut yaitu: (a) guru meningkatkan intensitas bimbingan dan pengawasan kepada siswa dalam pembelajaran; (b) guru memberikan motivasi serta kesempatan terbuka kepada semua siswa agar siswa aktif dalam mengikuti pembelajaran; (c) guru lebih cermat dalam menggunakan waktu pembelajaran; (d) guru membagi tugas kepada siswa dalam kelompok agar seluruh siswa berperan aktif dalam menyelesaikan tugas kelompok. Kata kunci : inkuiri terbimbing, aktivitas belajar, hasil belajar 


\section{PENDAHULUAN}

IImu Pengetahuan Alam (IPA) merupakan salah satu mata pelajaran yang mendorong siswa dalam proses perubahan perilaku sebagai hasil interaksi dengan lingkungan untuk mencapai tujuan pembelajaran. Depdiknas (2003: 27) menyebutkan bahwa tujuan utama pembelajaran IPA disekolah dasar adalah agar siswa dapat memahami konsep-konsep IPA secara sederhana dan mampu menggunakan metode ilmiah, bersikap ilmiah, guna memecahkan masalah-masalah yang dihadapi dengan lebih menyadari kebesaran dan kekuasaan pencipta alam. Proses pembelajaran IPA menitikberatkan pada memberian pengalaman secara langsung kepada siswa agar dapat mengembangkan kompetensi yang sudah dimiliki oleh siswa unuk memahami alam sekitar.

Pembelajaran IPA adalah suatu pembelajaran yang tidak hanya dilihat dari hasil belajar saja, tetapi juga dilihat pada proses pembelajarannya yang memberi kesempatan agar siswa dapat menunjukan keaktifan penuh dalam pembelajaran (active learning), serta dapat menciptakan suasana menyenangkan bagi siswa sehingga siswa dapat mengikuti pembelajaran sengan nyaman dan menyenangkan (joyfull learning) (Sulistyorini dan Supartono, 2007: 8).

Menurut Dave Meier aktivitas harus dilakukan dalam kegiatan belajar, yaitu saat menggerakan fisik ketika belajar, memanfaatkan indera semaksimal mungkin, dan menggunakan tubuh serta pikiran untuk berperan dalam proses belajar (Yamin, 2010: 74).

Menurut Paul D. Dierich (Yamin, 2010: 84), aktivitas dalam proses pembelajaran dapat terlihat pada kegiatan-kegiatan yang dilakukan selama pembelajaran meliputi: 1) kegiatan visual, 2) kegiatan lisan, 3) kegiatan mendengarkan, 4) kegiatan menulis, 5) kegiatan menggambar, 6) kegiatan metrik, 7) kegiatan mental, dan 8) kegiatan emosional.

Berdasarkan hasil pengamatan pada kegiatan pembelajaran dan wawancara yang dilakukan peneliti dengan guru kelas, diperoleh informasi bahwa pembelajaran IPA yang dilaksanakan di SD Negeri 3 Kalirejo yaitu: (1) pembelajaran kurang bermakna bagi siswa karena siswa tidak diberikan kesempatan untuk menemukan fakta dan konsep sendiri, (2) pembelajaran hanya melibatkan beberapa siswa yang aktif sedangkan siswa yang lain kurang memperhatikan pelajaran, (3) pembelajaran yang dilaksanakan kurang inovatif menjadikan beberapa siswa bosan dan rasa ingin tahu siswa masih rendah, (4) pembelajaran bersifat teacher center yaitu metode ceramah yang mendominasi pembelajaran, sehingga aktivitas siswa dalam pembelajaran IPA rendah, (5) hasil belajar IPA rendah karena terdapat 48\% dari 25 siswa yang mendapatkan nilai di bawah KKM $(\mathrm{KKM}=70)$.

Berdasarkan masalah tersebut, perlu adanya inovasi terhadap metode yang digunakan saat pembelajaran untuk meningkatkan aktivitas siswa dalam pembelajaran IPA sehingga dapat memberi kemungkinan agar siswa dapat menunjukkan keaktifan yang optimal dalam proses belajar, serta dapat meningkatkan hasil belajar siswa.

Menurut Piaget model pembelajaran inkuiri terbimbing merupakan model yang tepat untuk mempersiapkan siswa untuk melakukan eksperimen, sehingga siswa melihat secara langsung apa yang terjadi, melakukan secara langsung, mengajukan pertanyaan-pertanyaan, mencari jawabannya sendiri, serta menghubungkan penemuan yang satu dengan penemuan yang lain dan membandingkan sesuatu yang ditemukannya dengan yang ditemukan siswa lain (Mulyasa, 2009: 109).

Menurut penelitian yang dilakukan oleh Matthew dan Kenneth (2013) dibuktikan bahwa siswa yang mengikuti pembelajaran dengan menggunakan model inkuiri terbimbing siswa dituntut untuk dapat memecahkan permasalahan secara langsung sehingga siswa mendapatkan prestasi yang lebih baik dibandingkan dengan mengikuti pembelajaran konvensional. 
Penerapan model inkuiri terbimbing menurut Sanjaya (2013: 202) dilakukan dengan langkah-langkah : (1) orientasi, (2) merumuskan masalah, (3) mengajukan hipotesis, (4) mengumpulkan data, (5) membuktikan hipotesis, (6) menarik kesimpulan

Berdasarkan uraian di atas, rumusan masalah pada penelitian ini adalah : (1) bagaimana penerapan model pembelajaran inkuiri terbimbing dalam peningkatan aktivitas dan hasil belajar IPA tentang gaya di kelas V SD Negeri 3 Kalirejo tahun ajaran 2017/2018?,

(2) apakah penerapan model pembelajaran inkuiri terbimbing dapat meningkatkan aktivitas belajar di kelas V SD Negeri 3 Kalirejo tahun ajaran 2017/2018?, (3) apakah penerapan model pembelajaran inkuiri terbimbing dapat meningkatkan hasil belajar IPA tentang gaya di kelas V SD Negeri 3 Kalirejo tahun ajaran 2017/2018?, (4) apakah kendala dan solusi pada penerapan model pembelajaran inkuiri terbimbing dalam peningkatan aktivitas dan hasil belajar IPA tentang gaya di kelas V SD Negeri 3 Kalirejo tahun ajaran 2017/2018?

Tujuan penelitian ini (1)mendeskripsikan penerapan model pembelajaran inkuiri terbimbing dalam peningkatan aktivitas belajar dan hasil belajar IPA tentang gaya di kelas V SD Negeri 3 Kalirejo tahun ajaran 2017/2018, (2) meningkatkan aktivitas belajar di kelas V SD Negeri 3 Kalirejo tahun ajaran 2017/2018 dengan penerapan model pembelajaran inkuiri terbimbing, (3) Meningkatkan hasil belajar IPA tentang gaya di kelas V SD Negeri 3 Kalirejo tahun ajaran 2017/2018 dengan penerapan model pembelajaran inkuiri terbimbing, (4) Mendeskripsikan kendala dan solusi dalam penerapan model pembelajaran inkuiri terbimbing dalam peningkatan aktivitas belajar dan hasil belajar IPA tentang gaya di kelas V SD Negeri 3 Kalirejo tahun ajaran 2017/2018.

\section{METODE}

Penelitian direncanakan akan dilaksanakan di SD Negeri 3 Kalirejo selama 6 bulan, yaitu mulai bulan Oktober 2017 sampai Maret 2018 dengan subjek penelitian adalah siswa kelas V SD Negeri 3 Kalirejo tahun ajaran 2017/2018, dengan jumlah sebanyak 25 siswa yang terdiri dari 13 siswa laki-laki dan 12 siswa perempuan.

Data diperoleh bersumber dari guru dan siswa kelas $\mathrm{V}$. Teknik pengumpulan data yang digunakan peneliti yaitu teknik tes (tes hasil belajar) dan non tes (observasi, wawancara, dan dokumentasi). Data yang diperoleh berupa data kuantitatif (nilai hasil belajar siswa dan skor lembar observasi), dan data kualitatif (informasi dan deskripsi proses belajar). Data tersebut diuji validitasnya dengan menggunakan triangulasi sumber dan teknik. Kemudian data tersebut dianalisis dengan menggunakan model analisis data menurut Miles dan Huberman, yang meliputi reduksi data, penyajian data, dan penarikan kesimpulan (Sugiyono, 2011: 246).

Indikator kinerja penelitian yang ditargetkan dalam penelitian ini, yaitu $85 \%$ untuk aspek penerapan model pembelajaran inkuri terbimbing, aspek aktivitas belajar ditargetkan sebesar $85 \%$, dan aspek ketuntasan hasil belajar IPA sebesar $85 \%$ dengan $\mathrm{KKM}=70$.

\section{HASIL DAN PEMBAHASAN}

Penerapan model pembelajaran inkuiri terbimbing untuk meningkatkan aktivitas dan hasil belajar IPA tentang gaya di kelas V SD Negeri 3 Kalirejo dilakukan selama tiga siklus, pada siklus I terdiri dari dua pertemuan, siklus II terdiri dari dua pertemuan, dan siklus III terdiri dari satu pertemuan, dengan alokasi waktu 2x 35 menit setiap pertemuan.

Pelaksanaan model pembelajaran inkuiri terbimbing meliputi enam langkah yaitu: (1) orientasi, (2) merumuskan masalah, (3) mengajukan hipotesis, (4) mengumpulkan data (5) membuktikan hipotesis, (6) menarik kesimpulan. Langkah tersebut sesuai dengan pendapat Sanjaya (2013: 202) . 
Penerapan model pembelajaran inkuiri terbimbing pada pembelajaran IPA tentang gaya skor yang diperoleh mengalami peningkatan pada setiap siklus. Hasil observasi penerapan model pembelajaran inkuiri terbimbing terhadap guru dapat dilihat pada tabel 1:

Tabel 1. Hasil observasi model inkuiri terbimbing terhadap guru

\begin{tabular}{cccc}
\hline \multirow{2}{*}{ Langkah } & \multicolumn{3}{c}{ Persentase (\%) } \\
\cline { 2 - 4 } & Siklus I & Siklus II & Siklus III \\
\hline 1 & 84,72 & 93,06 & 97.22 \\
2 & 64,58 & 81,25 & 87.5 \\
3 & 70,83 & 83,33 & 91.67 \\
4 & 60,42 & 81,25 & 87.5 \\
5 & 77,08 & 87,50 & 91.67 \\
6 & 86,46 & 82.29 & 87.5 \\
\hline Rata- & $\mathbf{7 4 , 0 2}$ & $\mathbf{8 4 . 7 8}$ & $\mathbf{9 0 . 5 1}$ \\
rata & & & \\
\hline Kategori & $\mathbf{C}$ & $\mathbf{B}$ & $\mathbf{A}$ \\
\hline
\end{tabular}

Berdasarkan tabel 1 diketahui bahwa hasil obser/vasi penerapan model pembelajaran inkuiri terbimbing terhadap guru pada siklus I rata-rata yang didapatkan sebesar $74,02 \%$, kemudian terjadi peningkatan rata-rata yang terjadi pada siklus II menjadi $84,78 \%$, dan rata-rata yang didapatkan kembali terjadi peningkatan pada siklus III menjadi sebesar $90,51 \%$.

Sedangkan hasil observasi penerapan model pembelajaran inkuiri terbimbing terhadap siswa dapat dilihat pada tabel 2:

Tabel 2. Hasil observasi model inkuiri terbimbing terhadap siswa

\begin{tabular}{cccc}
\hline \multirow{2}{*}{ Langkah } & \multicolumn{3}{c}{ Persentase (\%) } \\
\cline { 2 - 4 } & Siklus I & Siklus II & Siklus III \\
\hline 1 & 83.33 & 88.89 & 94.45 \\
2 & 60.41 & 74.99 & 83.33 \\
3 & 58.33 & 83.33 & 91.67 \\
4 & 72.91 & 87.5 & 87.5 \\
5 & 75 & 83.33 & 87.5 \\
6 & 71.88 & 80.21 & 85.41 \\
\hline Rata-rata & $\mathbf{7 0 . 3 1}$ & $\mathbf{8 3 . 0 4}$ & $\mathbf{8 8 . 3 1}$ \\
\hline Kategori & $\mathbf{C}$ & $\mathbf{B}$ & $\mathbf{B}$ \\
\hline
\end{tabular}

Berdasarkan tabel 2 didapatkan rata-rata pada siklus I sebesar $70,31 \%$, kemudian rata-rata yang didapatkan meningkat pada siklus II menjadi $83,04 \%$, dan pada siklus III rata-rata yang didapatkan meningkat menjadi $88,31 \%$. Berdasarkan data tersebut dapat diketahui bahwa telah terjadi peningkatan pada setiap siklus dan pada siklus III sudah menjukan hasil yang optimal.

Selain proses pembelajaran menggunakan model pembelajaran inkuiri terbimbing, peneliti juga megambil data aktivitas dan hasil belajar siswa pada setiap pertemuan. Berikut disajikan hasil observasi aktivitas belajar siswa di tabel 3. 
Tabel 3. Hasil observasi aktivitas belajar siswa

\begin{tabular}{ccccc}
\hline \multirow{2}{*}{ Siklus } & \multicolumn{2}{c}{ Persentase (\%) } & $\begin{array}{c}\text { Rata- } \\
\text { rata }\end{array}$ & Ket. \\
\hline I & 62,66 & 72,04 & 67,35 & D \\
II & 79,88 & 84,12 & 82 & B \\
III & 87,08 & - & 87,08 & B \\
\hline
\end{tabular}

Aktivitas belajar siswa mengalami peningkatan pada siklus I, II, dan III. Rincian peningkatan hasil observasi aktivitas belajar siswa yaitu pada siklus I diperoleh persentase aktivitas belajar siswa sebesar $67,35 \%$ yang termasuk kategori rendah, pada siklus II persentase yang didapatkan sebesar $82 \%$ yang termasuk kategori baik, dan pada siklus III didapatkan persentase sebesar 87,08 yang termasuk kategori baik. Hasil akhir observasi aktivitas belajar siswa pada siklus III sudah mencapai target yang ditentukan yaitu $85 \%$. Hasil penelitian ini diperkuat dengan penelitian yang dilakukan oleh Erlina, Rede, A., \& Saehana, S. (2016: 1-7) yang menyatakan bahwa model pembelajaran inkuiri terbimbing memiliki keunggulan menjadikan siswa aktif karena memberikan pengalaman secara langsung, sehingga dapat meningkatkan aktivitas belajar siswa.

Berikut analisis hasil belajar siswa antarsiklus dapat dilihat pada tabel 4 berikut.

Tabel 4. Hasil Belajar IPA Materi Gaya

\begin{tabular}{ccccccc}
\hline \multirow{2}{*}{$\begin{array}{l}\text { Perte- } \\
\text { muan }\end{array}$} & \multicolumn{3}{c}{ Tuntas (\%) } & \multicolumn{3}{c}{$\begin{array}{c}\text { Belum Tuntas } \\
\text { (\%) }\end{array}$} \\
\cline { 2 - 7 } & I & II & III & I & II & III \\
\hline 1 & 75 & 80 & 96 & 25 & 20 & 4 \\
2 & 79,17 & 96 & - & 20,83 & 4 & - \\
\hline $\begin{array}{l}\text { Rata } \\
\text {-rata }\end{array}$ & 77,08 & 88 & 96 & 22,91 & 12 & 4 \\
\hline
\end{tabular}

Dari tabel 4 dapat diketahui bahwa ketuntasan hasil belajar siswa selalu mengalami peningkatan pada setiap siklus. Pada siklus I persentase siswa yang tuntas sebesar $77,08 \%$, pada siklus II sebesar $88 \%$, dan pada siklus III sebesar $96 \%$. Hasil akhir pada siklus III sudah mencapai target yang ditentukan. Sedangkan jumlah siswa yang belum tuntas selalu berkurang pada setiap siklus. Pada siklus I persentase siswa yang belum tuntas sebesar $22,91 \%$, pada siklus II sebesar $12 \%$, dan pada siklus III sebesar $4 \%$. Hasil tersebut menunjukan bahwa ketuntasan siswa telah mencapai indikator kinerja $85 \%$. Hasil penelitian tersebut sejalan dengan penelitian yang dilakukan oleh Nur, Kamaludin, dan Djirimu. (2014: 126-133) yang menyatakan bahwa pembelajaran melalui metode inkuiri terbimbing dapat meningkatkan hasil belajar siswa di kelas V SDN 2 Bora.

\section{SIMPULAN}

Berdasarkan hasil penelitian diperoleh kesimpulan sebagai berikut:

1. Penerapan model pembelajaran inkuiri terbimbing dalam peningkatan aktivitas dan hasil belajar IPA di kelas V SD Negeri 3 Kalirejo tahun ajaran 2017/2018 dilaksanakan dengan langkah-langkah meliputi: (1) orientasi, (2) merumuskan masalah, (3) mengajukan hipotesis, (4) mengumpulkan data, (5) membuktikan hipotesis, (6) menarik kesimpulan. 
2. Penerapan model pembelajaran inkuiri terbimbing dapat meningkatkan aktivitas belajar IPA tentang gaya di kelas V SD Negeri 3 Kalirejo tahun ajaran 2017/2018. Hal tersebut dibuktikan dengan adanya peningkatan keaktifan siswa dalam melaksanakan aktivitas belajar IPA pada siklus I diperoleh persentase aktivitas belajar siswa sebesar $67,35 \%$ yang termasuk kategori rendah, pada siklus II persentase yang didapatkan sebesar $82 \%$ yang termasuk kategori baik, dan pada siklus III didapatkan persentase sebesar $87,08 \%$ yang termasuk kategori baik serta sudah mencapai target pada indikator kinerja penelitian yaitu sebesar $85 \%$.

3. Penerapan model pembelajaran inkuiri terbimbing dapat meningkatkan hasil belajar IPA tentang gaya siswa kelas V SD Negeri 3 Kalirejo tahun ajaran 2017/2018. Hal tersebut dibuktikan dengan adanya peningkatan dari ketuntasan hasil belajar siswa pada siklus I sebesar sebesar $77,08 \%$, pada siklus II sebesar $88 \%$, dan pada siklus III sebesar $96 \%$.

4. Kendala yang dihadapi saat pembelajaran meliputi: (a) jumlah siswa yang cukup banyak menyebabkan guru sulit memberikan pengawasan dan bimbingan yang intensif terhadap siswa; (b) siswa tertentu yang terlibat aktif kegiatan pembelajaran; (c) pembelajaran memerlukan waktu yang lama; (d) beberapa siswa kurang memiliki kesadaran dalam menyelesaikan tugas kelompok. Solusi dari kendala tersebut yaitu: (a) guru meningkatkan intensitas bimbingan dan pengawasan kepada siswa dalam pembelajaran; (b) guru memberikan motivasi serta memberikan kesempatan terbuka kepada semua siswa agar siswa aktif dalam mengikuti pembelajaran; (c) guru harus lebih cermat dalam menggunakan waktu pembelajaran; (d) guru membagi tugas kepada siswa dalam kelompok agar semua siswa berperan aktif dalam menyelesaikan tugas kelompok.

\section{DAFTAR PUSTAKA}

Depdiknas. (2003). Undang-undang Republik Indonesia Nomor 20 Tahun 2003 Tentang Sistem Pendidikan Nasional. Jakarta: Departemen Pendidikan Nasional.

Erlina, Rede, A., \& Saehana, S. (2016). Penerapan Model Pembelajaran Inkuiri Terbimbing untuk Meningkatkan Aktivitas dan Hasil Belajar IPA Siswa Kelas V SD Inpres 2 Kayumaleu Ngapa. E-Jurnal Mitra Sains, 4(1) 1-7.

Matthew, B. M. dan Kenneth I. O. (2013). A Study on The Effect of Guided Inquiry Teaching Method On Students Achievement In Logic. International Research. 1(2), 135-140.

Mulyasa, E. (2009). Menjadi Guru Profesional: Menciptakan Pembelajaran Kreatif dan Menyenangkan. Bandung: Remaja Rosdakarya

Nur, Kamaludin, dan Djirimu. (2014). Penggunaan Metode Inkuiri Terbimbing untuk Meningkatkan Hasil Belajar Siswa pada Pokok Bahasan Tumbuhan Hijau di Kelas V SDN 2 Bora. Jurnal Kreatif Tadulako Online, 5(6): 126-133.

Sanjaya, W. (2013). Strategi Pembelajaran: Implementasi Standar Proses Pendidikan. Jakarta: Kencana Pramedia Group.

Sugiyono. (2011). Metode Penelitian Kuantitatif, Kualitatif, dan R\&D. Bandung: Alfabeta.

Sulistyorini, S. \& Supartono. (2007). Model Pembelajaran IPA Sekolah Dasar dan Penerapannya dalam KTSP. Yogyakarta: Tiara Wacana.

Yamin, M. (2010). Kiat Membelajarkan Siswa. Jakarta: Gaung Persada Press. 